\title{
Building Transfer Student Pathways for College and Career Success
}

Edited by: Mark Allen Poisel and Sonya Joseph

Reviewed by: Maria A. Sedotti, Director of Orientation Services, University of Connecticut, Storrs Campus

Building Transfer Student Pathways for College and Career Success makes a convincing case for why post-secondary institutions today need to reevaluate their definition of "transfer" and "transfer success," in addition to focusing on the pathways, programs, support services, and degree completion of this population.

The eight chapters in this book represent a significant collection of current research using national data, case studies, theory, and practice on the topic of transfer. It provides examples and recommendations to support transfer students, and the strategies that lead to best practices with this population. This publication is intended to provide practitioners with data and other information to help influence change and intentionally create institutional cultures where transfer students thrive. The editors of Building Transfer Student Pathways for College and Career Success are professionals who work and advocate for the unique and extremely important transfer population. This publication can be used as both a learning tool and a resource for the OTR professional when it comes to the transfer topic.

While many post-secondary institutions place heavy emphasis on direct entry pathways, students who choose to attend multiple institutions of higher learning are forming a critical mass among college attendees. Although the $2+2$ traditional student transfer pattern (community 
college to 4-year institution) still exists, more complex transfer pathways have emerged. According to this publication it is these complex transfer pathways that post-secondary institutions need to recognize, seriously consider, and accommodate in order to make the educational experience meaningful with the goal of decreasing their time to earn a degree.

Chapter 1, written by Douglas T. Shapiro, presents important data on the transfer population from the National Student Clearinghouse (NSC) Research Center. This data reveals that today's college students are increasingly mobile. The data analysis by Shapiro is significant and sets the scene for the chapters that follow. The NSC defines post-secondary student "mobility" as a transfer beyond the traditional pathway. Based on research, students are moving from one institution to another for courses, credits, and programs of study in large numbers, high frequencies, and multiple patterns. (Shapiro, 2018, p. 1). The phenomenon of mobility can be expanded to include students enrolled at multiple institutions at one time, or those who take courses not followed by a formal transfer of credits from one institution to another. Consequently, the many variations within the concept of mobility make it complex.

Based on NSC data, over half of all students on a typical campus are, on average, mobile students: they came from somewhere else, will go somewhere else, or both before finishing a degree (Shapiro, 2018, p. 3). This chapter also includes data from the NSC's Time to Degree Completion Report for 2015-2016, which distinctly reveals achieving a bachelor's degree in four years is not a common pathway even without a transfer (Shapiro, 2018, p.7). The data analysis done by Shapiro is eye opening and extremely informative for today's practitioners and should affect the way we think about transfer.

This publication contains case studies and examples of best practices and programs that illustrate pathways toward transfer success (success = degree completion). The importance of strategic partnerships on and off campus, along with strong support from staff and the development of clear pathways, are key in the degree completion effort for transfers. The detailed explanation of the "Tennessee Reverse Transfer Program" in Chapter 2 describes the efforts made to create an educational pathway 
where a community college student can transfer to a 4-year college and complete an associate's degree while working on the 4-year degree. This case study describes the state effort involved to put this plan in place. The description also includes a helpful summary on what worked, what did not work, and recommendations going forward.

Two model pathway programs in different states (Arizona and Florida) that involve community college systems and large, public universities are described in Chapter 3. One program known as MAPP (Maricopa to Arizona State University Pathways Program) is highly successful. In this program, students at Maricopa Community Colleges are guaranteed admission to specific degree programs and majors at Arizona State University if they follow a specific pathway. The second model pathway known as "Direct Connect to the University of Central Florida" (UCF) is similar to MAPP in that students who attend Valencia Community College are guaranteed admission to the bachelor's programs at the University of Central Florida. What is impressive about Direct Connect is that participants in this program make up the larger share of new students at UCF as compared to first-year students.

The goal of these two pathway programs is to provide a simple and clear pathway to degree completion between a community college and a 4-year institution with no surprises for the transfer. These programs provide students with clarity about what coursework to take at their community college so they can simultaneously complete their associate and bachelor's degree requirements. Joyce C. Romano and Maria L. Hesse describe a model for "Transfer Readiness" which includes six dimensions that they advocate can help students earn their bachelor's degree if they earned their associate's degree first. (Romano \& Hesse, 2018, p. 38-40). I found the information in this chapter very useful for program planning and implementation, especially Romano and Hesse's Transfer Readiness model.

Transfer orientation program development, planning and implementation is presented in Chapter 4. In this chapter, Stephanie M. Foote makes an important point that orientation programs for the transfer population must be developed with the specific needs of the transfer in mind. In addition, the development of a transfer orientation program 
should be guided by student development theory. This chapter described different orientation models (one day vs. two day), gave institutional examples of Transfer Orientation programs, and discussed the importance of program standards, assessment, and evaluation.

One of the most important points made in Chapter 4 is that before a transfer orientation program is planned an institutional profile of the transfer student should be completed to ensure that this population's needs are being met at orientation. This information is extremely critical not only for the creation of a successful transfer orientation program, but also for informing the institution about the nature of their specific transfer student population which can change over time. Another important suggestion is that transfers should be exposed to High Impact Practices (HIPS) implemented at their new post-secondary institution during orientation. Research has shown that transfer students participate in HIPS at lower rates than their peers (Foote, 2018, p. 55). Although I am very familiar with transfer orientation programming, I did find some thoughtprovoking information in this chapter.

Chapter 5 focuses on the critical importance of academic advising in terms of transfer success and degree completion. This chapter discusses the ways in which advising can anticipate, plan, and respond to the major challenges of transfer students. Topics include an explanation of the documented "transfer shock" phenomenon along with some of its possible causes and consequences. A transfer advising timeline is illustrated which begins prior to enrollment. In addition, basic academic advising information and planning is discussed along with a review of the transfer credit evaluation process.

I found Chapter 6, which focused on the topic of learning communities as efforts that mitigate the effects of stereotype threat, extremely interesting. Stereotype threat is the phenomenon where individuals perform more poorly on a task when a relevant stereotype or stigmatized social identity is made prominent in a performance situation. Stereotype threat has been repeatedly shown to adversely affect students' academic performance (Plinske, 2018, p. 93). According to this chapter, educational efforts to mitigate the effects of stereotype threat 
need to focus on increasing and enhancing a student's sense of belonging. One practice that helps this is to have students participate in learning communities, a High Impact Practice (HIP). Valencia Community College's Osceola campus created a number of cohort programs structured as learning communities to foster a student's sense of belonging and increase the likelihood of their success. This chapter describes how learning communities help students overcome stereotype threat and connect them to the campus community. It also describes the challenges of maintaining non-residential learning communities. The information in this chapter can be used as a guide for setting up this HIP practice at a community college.

The final chapter of this publication is on assessment. It reviews changing policy and trends related to transfers and highlights how careful assessment of transfer initiatives can influence transfer student success. Since transfer mobility is complex, alternative assessment models for transfer students have been developed to measure achievement and learning. Two examples in this chapter are SAM (The Student Achievement Measure) and VALUE (Valid Assessment of Learning in Undergraduate Education). SAM was developed to gather a more inclusive cohort of students, including those who have enrolled at more than one institution during their college career. This measure allows for a more expanded definition of success and more representative of the diversity student populations in institutions across the country. Besides these two assessment measures this chapter provides other types of data that can be used in the assessment process.

As a professional who has been in the field of OTR for 30+ years, I found the information in Building Transfer Student Pathways for College and Career Success to be extremely interesting and useful. The data from the NSC was compelling in proving that the transfer population follows non-traditional and complex pathways that educational institutions need to be aware of in order to cultivate and graduate this population in a timely manner. The case studies and best practices in this book are ones that can be replicated or partially replicated depending on the postsecondary institution. I especially appreciated the advice given in these examples. Another key takeaway is that the success of any educational 
effort to attract, educate, and graduate transfer students has to come through partnerships both in and out of the educational institution, along with a strong commitment from the administration, faculty, and staff of that post-secondary institution. Reaching the transfer population and serving them effectively must be in the strategic plans of a post-secondary institution. I took a lot of useful information from this publication and highly recommend reading Building Transfer Student Pathways for College and Career Success if you are an OTR professional. 